\title{
Trivium
}

Revue franco-allemande de sciences humaines et sociales - Deutsch-französische Zeitschrift für Geistesund Sozialwissenschaften

29 | 2019

Regards croisés sur le prophète de l'Islam

\section{Abréviations utilisées dans les bibliographies / In den Literaturlisten benutzte Abkürzungen}

\section{OpenEdition}

\section{Journals}

Édition électronique

URL : http://journals.openedition.org/trivium/6538

DOI : $10.4000 /$ trivium.6538

ISBN : 1963-1820

ISSN : 1963-1820

Éditeur

Les éditions de la Maison des sciences de l'Homme

Référence électronique

"Abréviations utilisées dans les bibliographies / In den Literaturlisten benutzte Abkürzungen »,

Trivium [Online], 29 | 2019, online erschienen am 18 Oktober 2019, abgerufen am 08 September 2020

URL : http://journals.openedition.org/trivium/6538; DOI : https://doi.org/10.4000/trivium.6538

Ce document a été généré automatiquement le 8 septembre 2020.

\section{cc)}

Les contenus des la revue Trivium sont mis à disposition selon les termes de la Licence Creative

Commons Attribution - Pas d'Utilisation Commerciale - Pas de Modification 4.0 International. 


\section{Abréviations utilisées dans les bibliographies / In den Literaturlisten benutzte Abkürzungen}

\begin{tabular}{|l|l|}
\hline BEO & Bulletin des études orientales \\
\hline BGA & Bibliotheca geographorum Arabicorum \\
\hline BIFAO & Le Bulletin de l'Institut français d'archéologie orientale \\
\hline BSOAS & Bulletin of the School of Oriental and African Studies \\
\hline EI2 & Encyclopédie de l'islam, deuxième édition \\
\hline GAL & Carl Brockelmann, Geschichte der arabischen Litteratur \\
\hline GAS & Fuat Sezgin, Geschichte des arabischen Schrifttums \\
\hline Isl. & Der Islam \\
\hline JAOS & Journal of the American Oriental Society \\
\hline JE & The Jewish Encyclopedia \\
\hline JNES & Journal of Near Eastern Studies \\
\hline JOAS & Journal of Oriental and African Studies \\
\hline JRAS & Journal of the Royal Asiatic Society of Great Britain and Ireland \\
\hline JSAI & Jerusalem Studies in Arabic and Islam \\
\hline
\end{tabular}




\begin{tabular}{|c|c|}
\hline MF & Ibn Taimīya, Mağmū al-fatāwā šaiH al-islām Aḥmad Ibn-Taimìya \\
\hline MISK & Mitteilungen zur Sozial- und Kulturgeschichte der islamischen Welt \\
\hline MSR & MuHtașār sīrat al-rasūl \\
\hline MT & mağmū'at at-tauhìd \\
\hline Muh. Stud. & Ignaz Goldziher, Muhammedanische Studien \\
\hline RAfr & Revue Africaine \\
\hline REI & Revue des études islamiques \\
\hline Remm & Revue des mondes musulmans et de la Méditerranée \\
\hline REMMM & Revue des mondes musulmans et de la Méditerranée \\
\hline RGG & Die Religion in Geschichte und Gegenwart \\
\hline RMM & Revue du Monde Musulman \\
\hline SI & Studia Islamica \\
\hline TN & Ḥusain b. Ġannām, TārīH Nağd \\
\hline WI & Die Welt des Islams \\
\hline ZDMG & Zeitschrift der Deutschen Morgenländischen Gesellschaft \\
\hline
\end{tabular}

